\title{
LA IMPORTANCIA DE LAS REDES FAMILIARES EN LOS PROCESOS DE REUNIFICACIÓN DE LOS LATINOAMERICANOS EN LOS ESTADOS UNIDOS
}

\author{
THE IMPORTANCE OF FAMILY NETWORKS ON THE REUNIFICATION \\ PROCESSES FOR LATIN-AMERICANS IN THE UNITED STATES
}

\section{A IMPORTAÇÃO DE REDES FAMILIARES NOS PROCESSOS DE REUNIÃO DOS LATINO-AMERICANOS NOS ESTADOS UNIDOS}

\author{
RUIZ-SANTACRUZ_J-Sebastian
}

\begin{abstract}
Doctor en Demografía del Centro de Estudios Demográficos, Universidad Autónoma de Barcelona. Investigador Grupo de investigación Estudios de Población y Demografía, Universidad Externado de Colombia e Investigador post-doctoral del Centro de Estudios Demográficos, Universidad Autónoma de Barcelona. E-mail: sebastianruizsantacruz@gmail.com, España.
\end{abstract}

Recibido: 30 de abril de 2020

Aprobado: 9 de junio de 2020

DOI: https://doi.org/10.22267/rtend.202101.127

\section{RESUMEN}

Los procesos migratorios incorporan diferentes estrategias que modifican las probabilidades de una nueva emigración. La existencia de una red de apoyo en muchos casos de familiares, funciona como un mecanismo de promoción de la migración. El objetivo de este estudio, es detallar cuáles eventos de reunificación son comunes en el desplazamiento de las familias y cuánto es el tiempo transcurrido entre las reunificaciones más habituales; es decir, entre cónyuges o entre padres e hijos. Para lograrlo, se estudia la reunificación con la información proveniente de las bases de datos de IPUMS-I e IPUMS-USA. La primera, permite analizar la composición de los hogares y observa el rol del sexo por tipo de reunificación, y la segunda, detalla qué variables influyen en el 
tiempo de reunificación de las categorías mencionadas. Los resultados muestran el predominio de tipos específicos de hogar y el cambio de tendencia en el tiempo, así como las variables significativas en el incremento o disminución del riesgo de reunificación.

Palabras clave: migración internacional, tendencias y previsiones demográficas, generalidades de modelos estadísticos, migración internacional, análisis de supervivencia.

JEL: C10, C21, C41, F22, J11

\begin{abstract}
The migratory processes incorporate different strategies that modify the probabilities of a new emigration. The existence of a support network, in many cases of family members, works as a mechanism to promote migration. The objective of this study is to detail which reunification events are common in the displacement of families and how much time elapses between the most common reunifications; that is, between spouses or between parents and children. To achieve this, the reunification with the information from the IPUMS-I and IPUMS-USA databases is studied. The first, allows analyzing the composition of households and observes the role of sex by type of reunification, and the second, details which variables influence the reunification time of the mentioned categories. The results show the predominance of specific types of household and the change in trend over time, as well as the significant variables in the increase or decrease in the risk of reunification.
\end{abstract}

Keywords: international migration, demographic trends and forecasts, general statistical models, international migration, survival analysis.

JEL: C10, C21, C41, F22, J11

\title{
RESUMO
}

Os processos migratórios incorporam estratégias diferentes que modificam as probabilidades de uma nova emigração. A existência de uma rede de apoio, em muitos casos de familiares, funciona como um mecanismo para promover a migração. O objetivo deste estudo é detalhar quais eventos de reunificação são comuns no deslocamento de famílias e quanto tempo decorre entre as reunificações mais comuns; isto é, entre cônjuges ou entre pais e filhos. Para isso, é estudada a reunificação com as informações das bases de dados IPUMS-I e IPUMS-USA. O primeiro, permite 
analisar a composição dos domicílios e observa o papel do sexo por tipo de reunificação, e o segundo detalha quais variáveis influenciam o tempo de reunificação das categorias mencionadas. Os resultados mostram a predominância de tipos específicos de famílias e a mudança de tendência ao longo do tempo, bem como as variáveis significativas no aumento ou diminuição do risco de reunificação.

Palavras-chave: migração internacional, tendências e previsões demográficas, modelos estatísticos gerais, migração internacional, análise de sobrevivência.

JEL: C10, C21, C41, F22, J11

\section{INTRODUCCIÓN}

Los procesos migratorios involucran diversas estrategias que promueven el desarrollo de la conexión entre un proceso individual y uno colectivo. En estos procesos, los hogares, como unidades de análisis, se encuentran inmersos bajo diversas presiones que modifican la toma de decisiones migratorias en conjunto con el desempeño de los colectivos emigrados. Igualmente, los sistemas migratorios han sido estudiados como la observación de movimientos que ocurren entre dos o más países que dentro de un contexto sobretodo económico, social y cultural y la tendencia que tomen (Kritz, Lim, y Zlotnik,1992). Esta evolución se estudia de manera retrospectiva desde hace tiempo por varios autores, entendiendo cómo es la respuesta del comportamiento de los flujos o los acumulados de migrantes bajo marcos políticos concretos, para así generar entendimiento sobre la realidad actual y las modificaciones que puedan hacerse a las reglamentaciones para su gobernanza, algo que en los últimos textos aparece como el estudio de los regímenes migratorios (Rass y Wolff, 2018).

El presente documento, se centra en el estudio de las formas familiares y su influencia sobre nuevos procesos de migración, algo que se presenta como un mecanismo dentro de los sistemas migratorios y que promueve una forma muy conocida de migración como lo es la reunificación. (Wallerstein, 1979 Hedström, y Bearman, 2009; Mabogunje, 1970; Kritz, Lim, y Zlotnik,1992; Bakewell, 2014; León-Medina, 2016). De este modo, se contempla la hipótesis en la que uno de estos mecanismos, que se expresa a través de la conformación redes familiares en destino, es determinante en la fuerza de atracción de un país por determinados colectivos (Jasso y Rosenweig, 1986). Lo anterior será comprobado mediante diferentes técnicas estadísticas para medir la rapidez 
diferenciada con la que se reunifican los miembros de cada una de las familias y los factores que inciden en ella.

\section{REFERENTES TEÓRICOS}

Hasta el momento en los Estados Unidos, el abordaje de la reunificación ha tenido un eje principal de discusión desde sus primeras interpretaciones mediante la ley pública de los Estados Unidos 89-236 de 1965, pasando por el concepto de cadena migratoria que, además de haber sido un objeto de amplio interés académico (Frizzell, 1987), es considerado como un mecanismo más en la consolidación y perpetuación de los sistemas migratorios que incorpora un elemento principal: el rol de la retroalimentación o feedback dentro de los mismos al impulsar nuevas migraciones (Mabogunje, 1970).

La reunificación familiar es un proceso en el cual intervienen diferentes variables que han sido estudiadas como parte de las políticas públicas estadounidenses y sus repercusiones sobre las familias latinoamericanas. Muchos de estos estudios se han dedicado a analizar entre otras cosas, la influencia de variables que miden los niveles educativos y las diferentes ocupaciones (Takenaka y Pren, 2010) y su influencia en los procesos migratorios. De este modo, la reunificación familiar es sin duda una de las variables que hace parte del cambio en la composición de las familias en el destino.

Otros debates, en los que se incluye la reunificación familiar, se desarrollan dentro del contexto de la inserción de los migrantes, y de los que se han generado gran cantidad de índices que permiten conocer el grado en que los migrantes han logrado casi que ingresar e insertarse en la sociedad de destino. Estos índices, la mayoría generados mediante encuestas, incorporan preguntas referentes a la reunificación familiar que indagan de manera más amplia sobre la accesibilidad a procesos administrativos para una rápida y segura reunificación tales como: permisos de residencia, de trabajo, menores acompañados y personas dependientes. Sin embargo, estas informaciones son incompletas frente a informaciones censales. Otro ejemplo de ello se da dentro de los estudios sobre el contexto del bienestar infantil, y sobre los servicios que se brindan a los niños que han sido puestos fuera de su hogar por razones familiares.

No obstante, el enfoque que se ofrece en este caso al estudiar las relaciones familiares de los latinoamericanos provenientes de Colombia, Ecuador, Perú, Bolivia y México, se enmarca en 
varios aspectos teóricos que provienen del entendimiento de las redes de migración y su labor como vehículo de inserción y reunificación en los países de destino. Las redes de migrantes se entienden como vínculos interpersonales que unen a familiares, amigos y miembros de la comunidad en sus lugares de origen y destino e influyen sobre la conformación familiar en el destino (Arriagada, 2007; Canales, 2017).

Un aspecto importante a tener en cuenta tiene que ver con la progresiva participación de la mujer y su rol en la migración de retorno. Sobre este aspecto particular, el trabajo no pretenderá mostrar todas las particularidades sobre el retorno de migrantes latinoamericanos, pero evidenciará, sin afirmar que ésta sea la única causa, cómo se ha afectado la composición de los hogares en el destino, modificando la estructura de las familias en las que se sabe incrementan su participación en actividades relacionadas con el trabajo doméstico y de cuidado en destino y los padres continúan engrosando las estadísticas de hogares que dejan atrás sus familias alterando su composición y reafirmando estereotipos basados principalmente en razones económicas y de estatus social (Pekin, 1989; Herrera, 2011; Nobles, 2013).

Como la información detalla solamente la conformación familiar, nos centraremos en este tipo de red para revisar lo que ocurre con la operación de la migración dentro de ellas. De allí que la reunificación se estudia por ser una de las formas conocidas de migración debido a la indudable dependencia entre tener uno o más familiares y el aumento en propensión de emigrar por parte de los que se han quedado atrás (Massey, 1990), algo definido como un factor multiplicador de la migración donde el número de familiares en destino resulta importante a la hora de considerar los tiempos de realizar la reunificación en el análisis de la probabilidad de su consecución (Jasso y Rosenweig, 1986).

Los modelos migratorios han intentado explicar los movimientos a través de la importancia del capital humano y los agregados poblacionales, pero éstos no han tenido en cuenta aspectos que atan las migraciones y hacen que su desarrollo sea diferencial dependiendo del colectivo (Massey y Aysa-Lastra, 2011). Así, los factores familiares, que se expresan a través del vínculo de parentesco, incorporan una manera de mirar estas diferencias. El concepto de red migratoria, en este caso, se encuentra muy relacionado con el de capital humano, lo que permite integrar las 
características individuales como el parentesco a factores explicativos de los procesos migratorios (Recaño, 2002; Gurak, y Kritz, M., 2016).

Este trabajo por tanto tiene como objetivo, estudiar la reunificación usando dos estrategias: la primera orienta la revisión de la composición de los hogares a través del tiempo desde 1980 hasta 2015 usando las muestras censales que ofrecen los datos colectados en IPUMS-Internacional (MPC, 2018) para Estados Unidos y del mismo modo. La finalidad de este análisis es la de comprender cómo son los arreglos familiares de los emigrados latinoamericanos y como ha sido su cambio durante el tiempo especialmente en la jefatura del hogar por ser esta figura la que comandará el análisis posterior.

La segunda, busca establecer las diferencias existentes en las formas y tiempos de reunificación, así como explorar el rol del sexo del jefe de hogar mediante un análisis transversal de más profundo de la muestra de la Encuesta de la Comunidad Americana (ACS por sus siglas en inglés). Esto a razón de que la variable tiempo para que se dé una reunificación es en general poco estudiada, sobre todo los beneficios que tiene al no tener que reconstruir denominadores de uno o 5 años antes para calcular tasas o propensiones (De Vos, S. 1987).

La aproximación se realizará con un estudio de caso en el que incluyen los colectivos provenientes de los países mencionados previamente. Los cuatro primeros son considerados por sus marcos políticos de integración en origen concretados por acciones entre países mediante tratados como el de la Comunidad Andina de Naciones (CAN), con lo que se introduce la hipótesis en la que dichos marcos afectan la distribución de población en toda la zona mediante las reunificaciones. De igual manera, se estudiará México como un sistema de referencia dado su volumen y estrategias de movilidad desarrolladas por su proximidad y su largo tiempo de formación (Martínez Pizarro, 2001).

\section{METODOLOGÍA}

La postura metodológica que presenta este artículo se enmarca dentro del análisis demográfico y otorga mayor relevancia a caracterizar la actividad de la reunificación y decidirse por una línea investigativa analítica-descriptiva. Para empezar, definiremos la conformación de hogar latinoamericano bajo estudio, a aquellos hogares emigrados en donde exista al menos un latinoamericano con o sin relación de parentesco. Para el análisis de las relaciones dentro de los 
hogares, se presentan los individuos dentro de categorías que intentan conservar la simpleza en una aproximación a las principales formas de convivencia recogidas en censos, encuestas y varios estudios sobre los tipos de conformación de los hogares (Laslett y Wall, 1972; Domingo y Bayona, 2010).

Se presenta entonces una clasificación de los hogares basada en los estudios previos en cuatro tipos principales Unipersonal: Hogar construido por una persona (jefe de hogar); Hogar nuclear: el hogar consiste en un núcleo conyugal de primera línea (jefe de hogar y cónyuge sin hijos, o jefe y cónyuge con hijos, o jefe con hijos) exclusivamente; Hogar extenso: hogar compuesto por un familiar no nuclear, otro pariente, exclusivamente nuclear; Hogar compuesto: el hogar consiste en un hogar nuclear o un hogar extendido más otros no parientes. Existe otro tipo de hogares definidos como Lugares especiales de Alojamiento (cárceles, batallones, seminarios, etc.) estos fueron omitidos del análisis, pero fueron considerados para calcular los porcentajes del resto sobre el total.

Así mismo, se examinarán las formas características de la reunificación familiar de los latinoamericanos en Estados Unidos, recogiendo los conteos y porcentajes de acuerdo a una tipología definida sobre la base de los tiempos de migración. Luego, se analizarán los estimadores de Kaplan-Meier para analizar los tiempos de reunificación para los principales colectivos latinoamericanos y por último se analizarán variables relevantes en la literatura sobre migraciones para probar modelos de Cox que den cuenta de cuales categorías de estas influyen significativamente sobre el tiempo de reunificación.

\subsection{Fuentes de datos}

Los datos proporcionados por IPUMS-International (Minessota Population Center, 2018) para los años 1980, 1990, 2000, 2005, 2010 y 2015, y la Encuesta de la Comunidad Americana (ACS) dispuesta en el repositorio IPUMS-USA (Ruggles et al., 2015). Los primeros permiten observar las formas de los hogares, incluyendo su desagregación por sexo y parentesco. También permite la identificación de tendencias en el tiempo respecto a la conformación. Posteriormente, se usarán los segundos, para probar modelos sobre los tiempos de supervivencia ya que contiene la variable que indica el año de matrimonio y permite diferenciar los hogares que se unieron en origen y que son más apegados a la definición de reunificación. 


\subsection{Estimador de Kaplan y Meier}

El análisis de supervivencia nos permite examinar simultáneamente el progreso de diferentes duraciones de un seguimiento (Woodward, 2014); el número de eventos (las reunificaciones) es analizado en lugar de revisar el mero hecho de que se produzcan. En nuestro caso, los tiempos de reunificación contarán desde la primera migración de un miembro de la familia (que puede ser el jefe del Hogar, el esposo/a o los hijos). Para este análisis no se consideran eventos censurados es decir ninguna salida de la cohorte, ni a izquierda (todos son mayores que cero al ser tiempos), ni derecha (ninguna fecha o tiempo de corte).

El enfoque de Kaplan-Meier (KM) se construye partiendo el periodo de seguimiento en intervalos consecutivos de tiempo, y se calculan los principales indicadores de la tabla de vida como por ejemplo el número de sobrevivientes ( $n_{t}$ : personas que no se han reunificado), la probabilidad de sobrevivir hasta un intervalo que comienza en el tiempo $t\left(p_{t}\right)$, el número de eventos en estudio al comienzo de un tiempo t $\left(e_{t}\right)$, la probabilidad de un evento a no sobrevivir, en nuestro caso, reunificarse $\left(q_{t}\right)$, y la probabilidad estimada de supervivencia desde la línea de base hasta el final del intervalo de estudio (st), descritas en las ecuaciones (1), (2) y (3):

$$
p_{t}=1-q_{t} . \quad q_{t}=e_{t} / n_{t} . \quad s_{t}=p_{0} p_{1} p_{2} \ldots p_{t-1}
$$

De este modo podemos definir la función de estimación del riesgo $\left(h_{t}\right)$ como en la ecuación (4):

$$
h_{t}=\frac{e_{t}}{n_{t} u_{t}} \text {. }
$$

Donde $e_{t}$ continúa siendo el número de eventos de reunificación en el tiempo $\mathrm{t}, n_{t}$ el número en riesgo (sobrevivientes o no reunificados). También suponemos que el tiempo para la próxima reunificación se encuentra $u_{t}$ unidades más lejano, con lo que el riesgo se mide en el intervalo t + $u_{t}$. Si no existen tiempos de reunificación repetidos, es siempre igual a 1. 


\subsection{Algunas consideraciones metodológicas}

Algunos retos a tener en cuenta para empezar, es que las muestras de IPUMS-Internacional debido a que no poseen la pregunta de si las parejas se han unido previamente en los países de origen, impulsa a tomar la decisión de trabajar los tiempos de reunificación con la muestra de IPUMSUSA, porque al contener la variable año de matrimonio y año de llegada, es posible filtrar quienes lo hayan hecho en sus países de origen, concretando una muestra más acorde al concepto de reunificación.

Además de esto, la información se toma de manera trasversal, por lo que las declaraciones sobre el rol dentro del hogar, sobre todo en el caso de ser jefe de hogar y esposo/a, pueden haber sido distintas en el momento de la primera migración de uno de los miembros. Sin embargo, es algo que no podemos observar de esta fuente y por esta razón, estudiaremos lo que se ha declarado al momento de la encuesta.

Por último, existe una limitación asociada a la información transversal dado que, al momento de la encuesta, no garantiza que las composiciones de los hogares se mantengan, sin embargo, debemos considerar que existe una dinámica en la formación de hogares, impulsada además por nuevos migrantes, y que generalmente es asociado con presiones económicas en el origen. Por lo tanto, no deberá tener sendas variaciones y, por el contrario, los espacios temporales entre las encuestas y censos pueden marcar una tendencia quinquenal desde el año 2000.

\subsection{Modelos de Cox}

Este tipo de modelos estadísticos se usa principalmente para modelar los datos recopilados a partir del estudio de seguimiento del tiempo hasta un evento, que se considera como la variable dependiente (Woodward, 2014). Para este análisis, se consideran todos los tiempos positivos para entender de esta manera la reunificación general entre los tipos de pareja.

Los modelos paramétricos del riesgo $\left(h_{t}\right)$ requieren de una distribución teórica de probabilidad para la especificación de los datos. Entre ellos, el modelo de riesgos proporcionales introducido por Cox en 1972, es el modelo de regresión más usado en el análisis de supervivencia. Su gran ventaja es, como lo hemos mencionado, que no requiere una forma particular de la distribución 
para los tiempos de supervivencia. Los modelos se ajustaron usando el paquete survival del software (R Core Team, 2017).

Cuando se deben comparar dos grupos (por ejemplo, los expuestos y los no expuestos a algunos factores que afecten el riesgo de reunificación), un supuesto que se hace a menudo es que la proporción de los riesgos para los grupos específicos (por ejemplo, expuestos divididos por no expuestos) son los mismos en todos los tiempos de supervivencia. A esto se le conoce como el supuesto de riesgos proporcionales $(\mathrm{PH})$ o modelo de Cox. Para nuestro caso el modelo no será evaluado entre expuestos y no expuestos ya que todos hacen parte de la primera categoría, por lo que dicho supuesto no puede ser evaluado más si puede usarse la regresión sobre los tiempos.

Para la parte donde se implementa los modelos de Cox, se utiliza la muestra IPUMS-USA que permite trabajar con el año de matrimonio y nos olvidaremos de quién llega primero, ya que nos interesa más el tiempo que pasa para la reunificación en general y las variables que inciden en él. Para este caso se han escogido, variables que son clásicas dentro de la literatura sobre la migración, y que en el contexto de la reunificación podemos examinar para determinar la importancia de estas en el jefe del hogar. Ellas reflejan una parte de los contextos socioeconómicos que proveen los países de origen. Puesto que las categorías son demasiadas, sobre todo para la variable ocupación, se ha escogido presentar únicamente las que son significativas.

Así, las variables y categorías consideradas son: Edad: Indica la edad en años a partir del último cumpleaños de la persona antes o en el día de la enumeración. Tiene como categoría de referencia para los modelos los menores de un año. Sexo: Reporta el sexo del que responde. 1: Hombre (categoría de referencia), 2: Mujer. Años desde Inmigración: Indica el número de años desde que una persona nacida en el extranjero emigró al país de enumeración. Nivel educativo: Registra el logro educativo de la persona en términos del nivel de escolaridad completado (grado u otro hito). Categoría de ocupación: Registra la ocupación principal de la persona, codificada según las categorías principales en el esquema de la Clasificación Internacional Uniforme de Ocupaciones (CIUO) de 2010.

De esta manera, se recogerán las variables que resultan significativas al 95\% de confianza en el modelo de Cox. Se usa las categorizaciones propuestas en IPUMS-USA para las variables incluidas. La ocupación que cuenta con 458 categorías iniciales que fueron reducidas a 27 . De este 
modo, se usará esta herramienta como modelo de diagnóstico, es decir, más allá de la interpretación numérica del riesgo que se puede obtener (en describir el tanto por ciento más o menos de riesgo que alguna categoría de la variable independiente incrementa o no los tiempos de reunificación), nos concentraremos en sintetizar los efectos, positivos (+) y negativos (-), y su influencia sobre la probabilidad de reunificación, es decir que otorgan riesgo o previenen el evento de reunificación.

\section{DISCUSIÓN}

\subsection{Presentación de resultados descriptivos}

Para la elección de los países se ha tomado como referencia los valores que corresponden a la clasificación de los 10 primeros en términos de la cantidad de migrantes usando los factores de expansión a la población y los casos en la muestra del 1\% de la ACS 2015, tal y como lo muestra la Tabla 1. En ella también se aprecian los porcentajes de éstos sobre la población total y sobre los latinos/hispanos reportados. De la misma forma se encuentra la razón de sexos (hombres/mujeres).

\section{Tabla 1}

Clasificación de población y porcentajes de latinoamericanos, frente al total de Estados Unidos y frente al colectivo declarado Hispano o Latino de cualquier procedencia

\begin{tabular}{|c|c|c|c|c|c|c|}
\hline País & $\begin{array}{l}\text { Población } \\
\text { en } \\
\text { censo } \\
\text { EE.UU. }\end{array}$ & $\begin{array}{l}\% \text { en } \\
\text { censo } \\
\text { EE.UU. }\end{array}$ & $\begin{array}{l}\text { \% sobre } \\
\text { Latinos/ } \\
\text { Hispanos }\end{array}$ & $\begin{array}{l}\text { Muestra } \\
\text { ACS, } 2015\end{array}$ & $\begin{array}{l}\% \text { en la } \\
\text { Muestra } \\
\text { ACS }\end{array}$ & $\begin{array}{l}\text { Razón de } \\
\text { sexos en la } \\
\text { muestra } \\
\text { ACS }(\mathrm{h} / \mathrm{m})\end{array}$ \\
\hline México & 11906325 & 3.70 & 23.59 & 93030 & 2.96 & 1.038 \\
\hline El Salvador & 1382737 & 0.43 & 2.74 & 10096 & 0.32 & 1.007 \\
\hline Cuba & 1225742 & 0.38 & 2.43 & 10517 & 0.33 & 0.924 \\
\hline Guatemala & 957721 & 0.30 & 1.90 & 6980 & 0.22 & 1.240 \\
\hline Colombia & 726766 & 0.23 & 1.44 & 5929 & 0.19 & 0.726 \\
\hline Haití & 700683 & 0.22 & 1.39 & 5020 & 0.16 & 0.835 \\
\hline Honduras & 610473 & 0.19 & 1.21 & 4097 & 0.13 & 1.010 \\
\hline Perú & 469658 & 0.15 & 0.93 & 3826 & 0.12 & 0.913 \\
\hline Ecuador & 455811 & 0.14 & 0.90 & 3355 & 0.11 & 0.832 \\
\hline Brasil & 376453 & 0.12 & 0.75 & 3423 & 0.11 & 0.849 \\
\hline
\end{tabular}


Total

Hispanos

ACS 2015. $\quad 3147005$

Total USA 321418821

Fuente: IPUMS-I, ACS 2015, elaboración propia.

$\mathrm{Al}$ analizar la población por edad y sexo de la muestra de personas que viven en los Estados Unidos de América y que han nacido en América Latina en el año 2015, es posible destacar como para Guatemala, El Salvador, Honduras y México existe un menor porcentaje de mujeres en la muestra. En el caso de otros países, se encontraron pirámides más femeninas de los países pertenecientes a la CAN, que se encuentran incluidos entre los primeros diez con más presencia como Colombia, Ecuador y Perú.

\subsection{Descripción de la composición de los hogares y el rol de sus integrantes}

Comencemos por analizar las configuraciones de los hogares con la tipología de hogares reconstruida. De este modo, si analizamos la Figura 1. las dos categorías de hogar más destacadas hasta el año 2010 son Nuclear y Extendida. No obstante, en 2015, los hogares nucleares tienen un descenso significativo debido al incremento de los hogares unipersonales en 11.2 puntos porcentuales desde el censo de 2010. De igual forma, de 1980 a 2000 se presentó un ligero descenso en el porcentaje de hogares nucleares, a diferencia de la familia extendida, que venía aumentando gradualmente. 


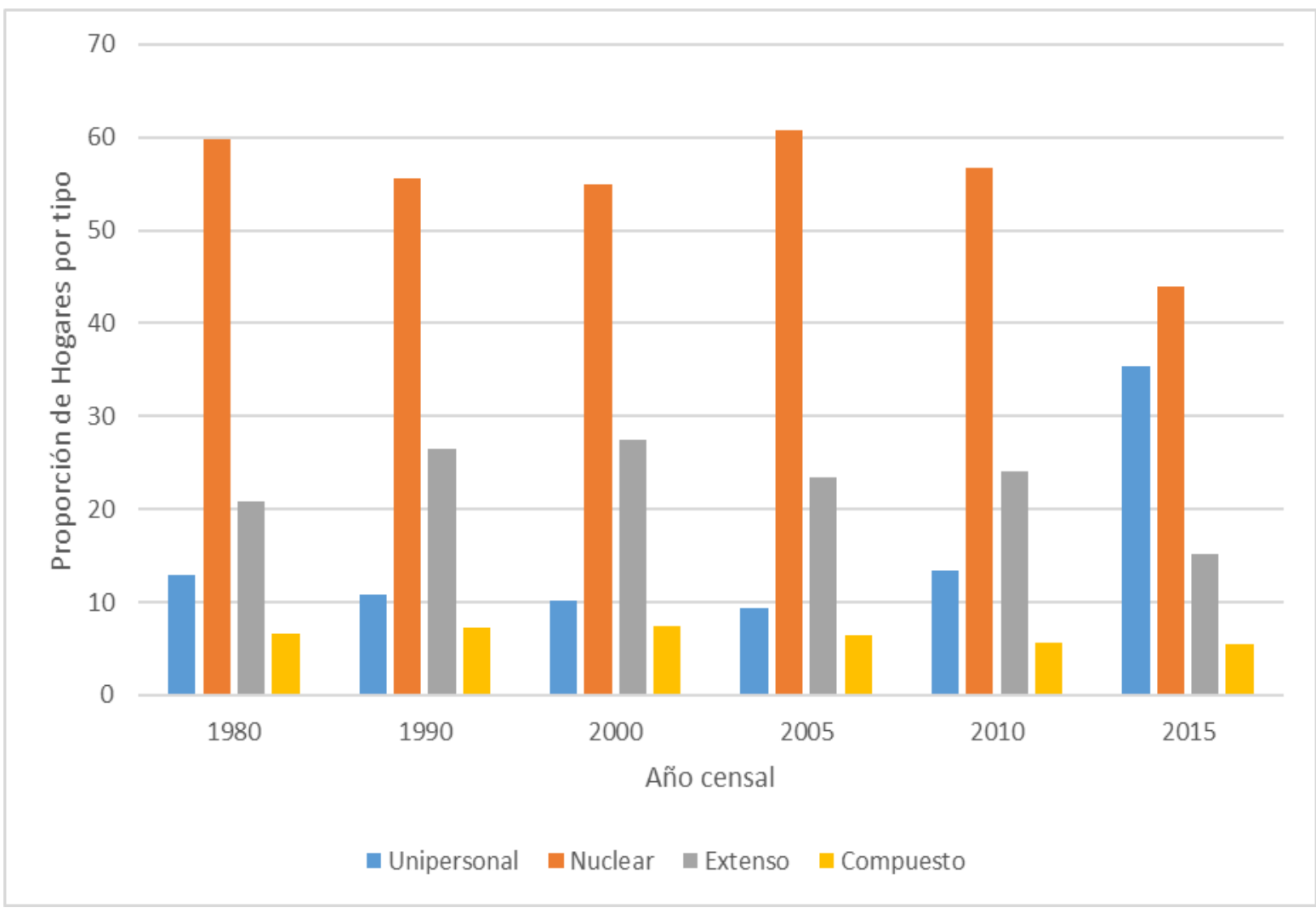

Figura 1. Porcentaje estimado basado en cuatro tipos de hogar de con al menos un Latinoamericano en Estados Unidos, 1980-2015.

Fuente: IPUMS-Internacional, elaboración propia.

No obstante, a partir de 2000 la tendencia se invierte. Los hogares unipersonales aumentaron de 9.4\% a 35.3\% en la última década registrada 2005-2015, lo que puede interpretarse como un efecto fuerte del retorno por la crisis presentada pero que debe considerar otras variables como la propia llegada de personas solas o el desplazamiento a terceros países.

La Tabla 2, ilustra cómo los hogares nucleares tienen porcentajes más altos en América del Sur que en América Central. De esta tabla diremos que para 2015, haciendo una clasificación para los cinco primeros países, es posible detallar que los porcentajes más altos de hogares del tipo unipersonal se presentan en el caso de Uruguay, Chile, Venezuela, Brasil y Colombia. Los hogares nucleares siguen un orden que algunos países de los anteriormente mencionados repiten: Paraguay, Chile, Uruguay, Brasil y Costa Rica. Cuando las clasificaciones se realizan por hogar extenso el orden que se establece es: El Salvador, Guatemala, Nicaragua, México y Honduras, y por hogar compuesto: Honduras, Guatemala, El Salvador, Perú y Colombia. 
Tabla 2

Porcentaje de tipo de hogar con al menos un latinoamericano por país de origen.

\begin{tabular}{lrrrr}
\hline Tipo & Unipersonal & Nuclear & Extenso & Compuestos \\
\hline Paraguay & 7.63 & 66.41 & 11.45 & 6.87 \\
Chile & 14.08 & 64.3 & 11.81 & 5.26 \\
Bolivia & 10.23 & 58.64 & 18.41 & 6.59 \\
Brasil & 13.51 & 61.87 & 9.36 & 6.69 \\
Uruguay & 16.44 & 62.67 & 12.67 & 5.14 \\
Colombia & 12.81 & 59.94 & 16.56 & 7.11 \\
Ecuador & 10.43 & 55.95 & 22.61 & 6.46 \\
Perú & 10.77 & 60.23 & 20.28 & 7.25 \\
Venezuela & 13.62 & 61.29 & 15.37 & 5.26 \\
Costa Rica & 12.21 & 61.4 & 15.8 & 6.03 \\
Guatemala & 6.59 & 52.4 & 25.85 & 9.91 \\
El Salvador & 6.37 & 52.32 & 27.45 & 7.96 \\
Nicaragua & 10.6 & 55.41 & 25.04 & 5.9 \\
Honduras & 8.81 & 50.97 & 23.11 & 10.09 \\
México & 7.62 & 58.94 & 23.27 & 5.11 \\
\hline Fute: & & & &
\end{tabular}

Fuente: IPUMS-USA, ACS 2015, elaboración propia.

Como resultados principales se pueden destacar entonces, que las composiciones de los hogares latinoamericanos en los Estados Unidos tienen una configuración similar, en la cual, la forma más común son los hogares nucleares, seguidos de los unipersonales. Estos últimos presentan una variación significativa en puntos porcentuales para todo el conjunto de los hogares latinoamericanos, especialmente desde el año 2010 al año 2015. Aún esto, persisten las diferencias regionales en cuanto a los porcentajes en destino.

Si a la par revisamos cifras sobre retorno podemos encontrar que, por ejemplo, México presenta una intensidad del retorno de hombres mayor que en las mujeres (64.4\%), principalmente en el grupo entre los 20 a los 44 años, esto además acentuado por su autodeclaración como responsables de familia (54.1\%) (Giorguli y Bautista, 2018). Otros autores muestran un comportamiento similar para el retorno desde Estados Unidos a países como Ecuador, Perú y Bolivia (Prieto, Pellegrino y Koolhaas, 2015), lo que coincidiría con los resultados del proceso de feminización de los 
colectivos en destino. Debe tomarse en cuenta que la gran mayoría de los retornados son personas solas que pueden afectar la interpretación, no obstante, no todo el aumento de las proporciones en los hogares unipersonales corresponde a los retornados ya que también se encuentran influenciados por situaciones de pobreza y el aumento de las mujeres en el mercado laboral.

Las relaciones de parentesco por sexo en la muestra ponderada de las personas que componen los hogares presentada en la Figura 2, se observa que el porcentaje de jefes de hogar hombres decrece paulatinamente con el tiempo, mientras que el crecimiento del mismo para las mujeres crece al punto de casi equiparar el porcentaje de los hombres en 2015. De la misma forma, es notorio como el porcentaje de hombres que se han declarado esposos crece, mientras que en las mujeres decrece al punto de ubicarse en 2015 por arriba del 20\%, debajo de las mujeres que se declararon jefes de hogar.

Además de esto, los que se han declarado como hijos mantienen un porcentaje del $35 \%$ en el grupo de los hombres, cercano de las declaradas como hijas en el de las mujeres. Esta tendencia se mantiene a lo largo del tiempo. Los parientes y no parientes se mantienen por debajo del 10\%. La única particularidad que se observa es que los no parientes hombres superaban para 1980 a los parientes y se ubican debajo de ellos solo hasta el año 2000. Tanto para hombres como para mujeres las variaciones de los porcentajes no parecen reflejar diferencias. Al final, las distribuciones parecen tener una equiparación con la excepción de tener más porcentaje de las que se han declarado como esposas. 


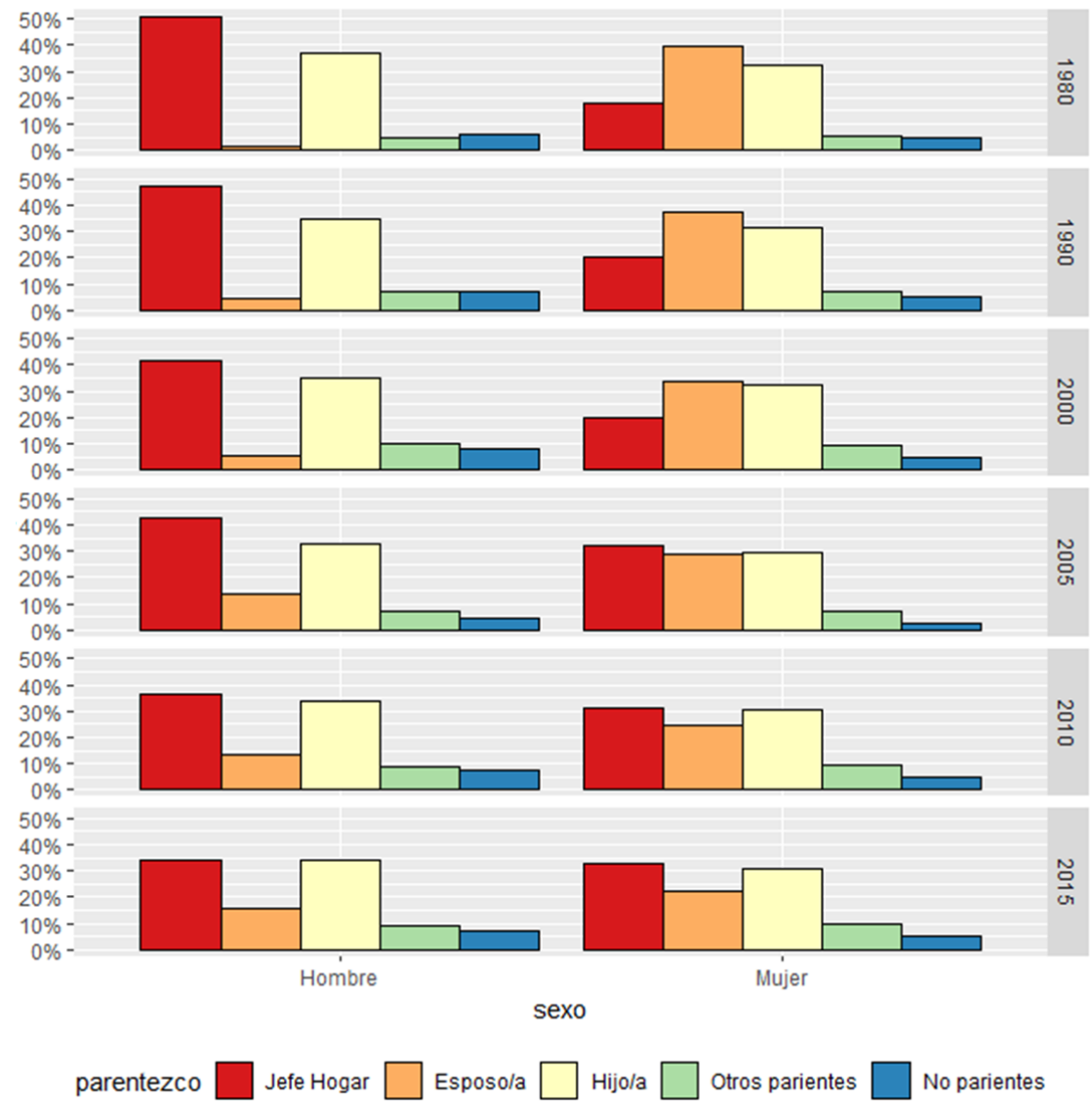

Figura 2. Porcentaje de la población en relación con el jefe de hogar para la muestra recogida de 1980 a 2015 en las muestras censales de IPUMS-Internacional usando los ponderadores para las personas.

Fuente: elaboración propia.

Igualmente, se evidencia un incremento de los porcentajes de participación femenina dentro del rol como jefe de hogar y su correspondiente descenso como esposa. También se resalta el rol del hombre como esposo dentro de las uniones detectadas desde 1980 hasta 2015. Del mismo modo, se registra el incremento de hogares unipersonales desde 2010 y el descenso de los hogares nucleares y extensos.

\subsection{Entendiendo las formas y tiempos de reunificación}

Para el caso de las formas y tiempos, vemos que la muestra de la ACS registra para el 2005 un total de 78097 hogares latinoamericanos, mientras que para el 2015 se obtienen un total de 106313. Los hogares con una persona han crecido, mientras que los hogares con dos personas o más parecen mantener los mismos porcentajes. Un primer dato sobre la organización es que de los migrantes provenientes de los países representados, al rededor del $75 \%$ se encuentra unido con connacionales por debajo de México, quien tiene el volumen más grande de migrados que llega a un $95 \%$ 
aproximadamente. Esto muestra que aún declarados nacionales de EE.UU. los mexicanos presentan una migración aparejada lo bastante fuerte a sus mismos coterráneos.

Al detallar la manera en que se dan las formas de los hogares latinoamericanos en relación con el jefe de hogar, su esposo/a y su lugar de nacimiento. Primero, con la muestra nos centraremos en analizar las parejas, jefe de hogar - esposo/a, y que son de igual país de nacimiento. La Tabla 3 muestra para el 2015 las parejas que para el momento censal se encontraban unidas y tenían de la misma nacionalidad, y que representan para los países de la CAN aproximadamente del 70 al 80 por ciento mientras que para México se encuentra en aproximadamente un 95\%. Destaca que la conformación de hogares con jefe de hogar unida con un esposo/a de otro país más alta sea la del colectivo peruano. Ya de entrada, la tabla nos muestra que los hogares latinoamericanos tienen preponderancia a estar conformados por connacionales.

\section{Tabla 3}

Porcentaje de personas que se encuentran unidas con personas nacidas en su mismo país y en otro país de Latinoamérica de acuerdo a la ACS, 2015

\begin{tabular}{llrr}
\hline \multirow{2}{*}{ País Jefe de Hogar } & $\begin{array}{l}\text { Esposo/as } \\
\text { Connacionales }\end{array}$ & \multicolumn{2}{c}{ Esposo/a de otro } \\
país & & Total casos \\
\hline México & & 4.46 & 21203 \\
Cuba & 86.15 & 13.84 & 1893 \\
Colombia & 79.05 & 20.95 & 1031 \\
Ecuador & 75.51 & 24.49 & 637 \\
Bolivia & 75.41 & 24.59 & 122 \\
El Salvador & 71.83 & 28.16 & 1850 \\
Perú & 71.32 & 28.68 & 631 \\
\hline
\end{tabular}

Fuente: ACS, 2015. IPUMS-USA. Elaboración propia.

La Tabla 4, nos muestra dos tipos de parejas migrantes y el orden de su migración: una es la que sucede entre el jefe de hogar y el esposo/a y viceversa (tipo 1) y entre el jefe de hogar y los hijos (tipo 2) y viceversa. En este punto, Bolivia ya muestra un bajo número de casos que lo dejará más adelante fuera de nuestros análisis debido a la necesidad de los mismos para las desagregaciones de la tipología. La Tabla 4, corresponde a la misma muestra de la ACS 2015 pero, con mucho más 
detalle sobre la fecha de matrimonio y su utilidad para filtrar la muestra por los que se han casado en origen. Esto cuando el jefe de hogar es hombre y cuando es mujer. De esta manera se incluye el rol del género dentro de la reunificación para discernir qué países destacan. De la misma tabla se recoge que, la reunificación que se da entre el jefe de hogar y el esposo/a, presenta mayores porcentajes cuando el primero es hombre, como en los casos de Ecuador, El Salvador y México. Las parejas que migran al mismo tiempo exhiben los más altos porcentajes.

En el caso de los hijos, se tiene una situación similar cuando migra primero el jefe de hogar y luego el hijo. Aquí son más altos los porcentajes para El Salvador y México cuando el primero es mujer siendo el jefe de hogar. Además, en el caso de la secuencia hijo-jefe de hogar, sigue siendo dominada por el sexo femenino para cuatro de los cinco países seleccionados.

\section{Tabla 4}

Porcentaje por sexo y según tipo de reunificación para los países seleccionados de la muestra no ponderada

\begin{tabular}{|c|c|c|c|c|c|c|c|c|c|}
\hline $\begin{array}{l}\text { De las } \\
\text { parejas de } \\
\text { igual } \\
\text { nacionalidad }\end{array}$ & $\begin{array}{l}\text { Sexo } \\
\text { jefe de } \\
\text { hogar }\end{array}$ & $\begin{array}{l}\text { Jefe de } \\
\text { hogar - } \\
\text { Esposo/a }\end{array}$ & $\begin{array}{l}\text { Esposo/a } \\
\text { - Jefe de } \\
\text { hogar }\end{array}$ & $\begin{array}{l}\text { Al } \\
\text { mismo } \\
\text { tiempo }\end{array}$ & $\begin{array}{l}\text { Total } \\
\text { parejas } \\
\text { tipo } 1\end{array}$ & $\begin{array}{l}\text { Jefe de } \\
\text { Hogar - } \\
\text { Hijo/a }\end{array}$ & $\begin{array}{l}\text { Hijo/a - } \\
\text { Jefe de } \\
\text { hogar }\end{array}$ & $\begin{array}{l}\mathrm{Al} \\
\text { mismo } \\
\text { tiempo }\end{array}$ & $\begin{array}{l}\text { Total } \\
\text { parejas } \\
\text { tipo } 2\end{array}$ \\
\hline \multirow[t]{2}{*}{ Colombia } & Hombre & 20.9 & 13.3 & 65.9 & 211 & 25.5 & 7.0 & 67.5 & 157 \\
\hline & Mujer & 4.9 & 34.4 & 60.7 & 61 & 23.1 & 11.5 & 65.4 & 104 \\
\hline \multirow[t]{2}{*}{ Ecuador } & Hombre & 31.2 & 15.6 & 53.2 & 109 & 51.7 & 6.9 & 41.4 & 87 \\
\hline & Mujer & 7.0 & 55.8 & 37.2 & 43 & 55.8 & 10.4 & 33.8 & 77 \\
\hline \multirow[t]{2}{*}{ Perú } & Hombre & 29.7 & 10.8 & 59.5 & 158 & 38.7 & 8.7 & 52.7 & 150 \\
\hline & Mujer & 8.3 & 33.3 & 58.3 & 48 & 30.0 & 3.8 & 66.3 & 80 \\
\hline \multirow[t]{2}{*}{ Bolivia } & Hombre & 33.3 & 16.7 & 50.0 & 36 & 26.9 & 7.7 & 65.4 & 26 \\
\hline & Mujer & 11.1 & 44.4 & 44.4 & 9 & 25.0 & 33.3 & 41.7 & 12 \\
\hline \multirow[t]{2}{*}{ México } & Hombre & 37.0 & 26.6 & 36.4 & 2751 & 50.0 & 8.8 & 41.3 & 2891 \\
\hline & Mujer & 13.1 & 8.9 & 78.1 & 1026 & 29.6 & 9.6 & 60.8 & 2570 \\
\hline \multirow[t]{2}{*}{ El Salvador } & Hombre & 38.2 & 20.8 & 41.0 & 212 & 60.4 & 6.1 & 33.5 & 245 \\
\hline & Mujer & 10.5 & 54.7 & 34.9 & 86 & 62.4 & 5.3 & 32.3 & 226 \\
\hline
\end{tabular}




\begin{tabular}{rrrrrrrrrr} 
Cuba & Hombre & 12.7 & 11.3 & 76.0 & 600 & 29.3 & 9.7 & 61.0 & 351 \\
& Mujer & 7.8 & 19.4 & 72.8 & 283.0 & 15.3 & 10.7 & 74.0 & 411 \\
\hline
\end{tabular}

Fuente: ACS, 2015. IPUMS-USA. Elaboración propia.

\subsection{Estudio de tiempos de reunificación mediante el Estimador de Kaplan-Meier (KM)}

A partir de ahora, el análisis se enfocará en reconocer que países tienen estimaciones diferentes del estimador de Kaplan-Meier (KM) para los tiempos que se obtienen de la resta simple de los años de llegada de cada miembro de la familia. Si usamos este estimador para revisar la probabilidad de reunificación contando con un vector de tiempos (en años) dados por las diferencias entre el año de llegada del jefe de hogar $(\mathrm{CH})$ y los demás integrantes y viceversa. Así, lo muestra la figura para el caso de los tiempos de reunificación entre parejas para los cuatro países con poblaciones más significativas en la muestra.

Debe reconocerse que los intervalos de confianza se solapan, es decir que no son significativamente diferentes, sin embargo, en algunos de los países es evidente que la varianza depende del tamaño de la muestra y por tanto el tamaño de los intervalos. Los casos de México y El Salvador son los que mejor evidencian lo que resulta de tener una muestra suficiente para estimar intervalos de confianza robustos. No obstante, los países con buena muestra presentan diferencias significativas para algunos tiempos de reunificación tal y como lo indica la Figura 3, se ha excluido Bolivia por la poca armonía que representa tener poca muestra en los resultados gráficos de sus intervalos de confianza. De aquí en adelante el eje de las y es el estimador KM y el de las $x$ en es el tiempo en años. 

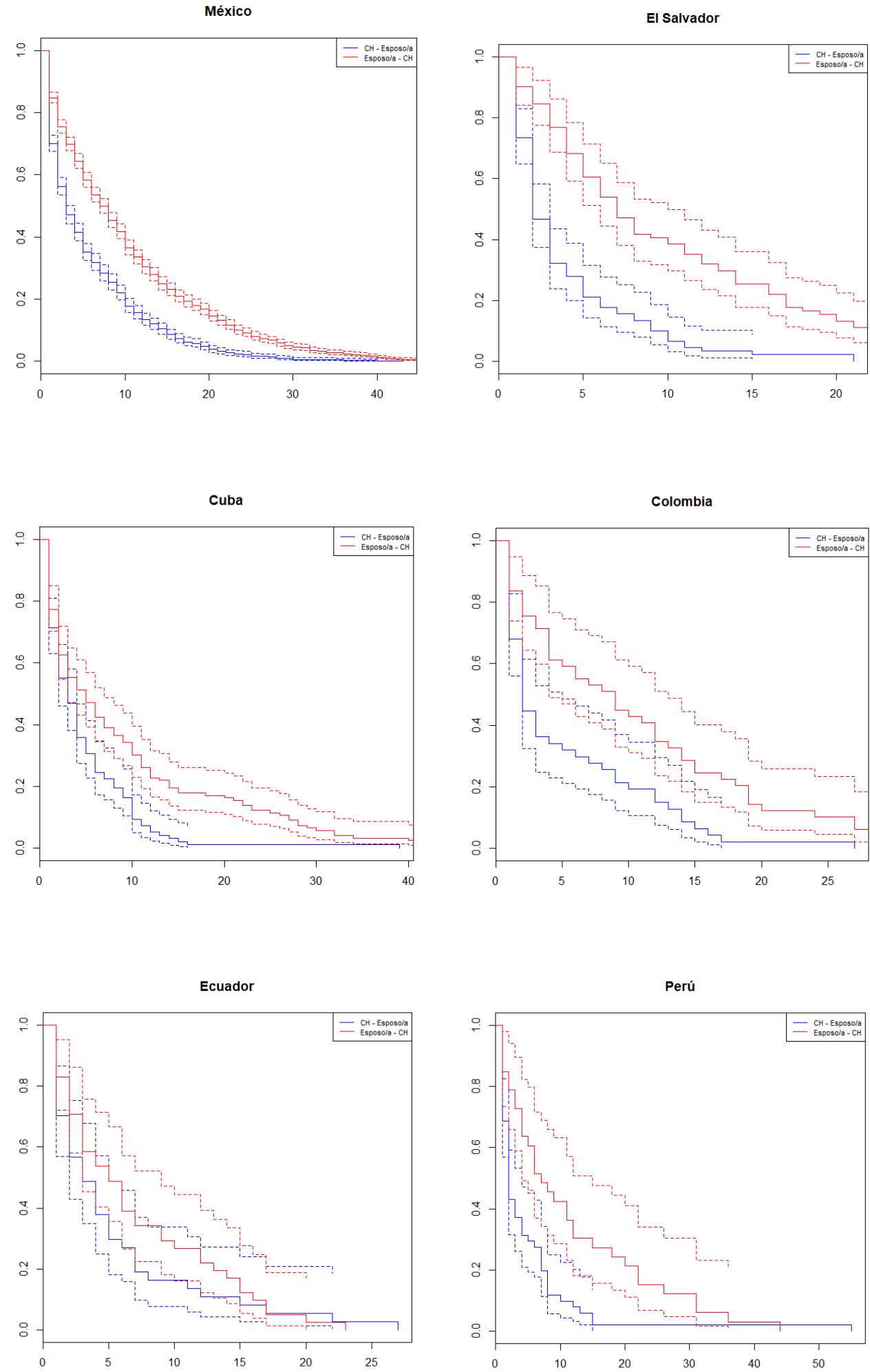

Figura 3. Estimador de Kaplan-Meier para el tiempo de reunificación cuando el jefe de hogar $(\mathrm{CH})$ migra primero que su pareja y viceversa.

Fuente: ACS, 2015. Elaboración propia. 
Lo primero que se observa para los países seleccionados es que los tiempos de reunificación son ligeramente mayores cuando migra primero el esposo/a, que cuando ha migrado primero el jefe de hogar. Cuando se compara por países: Ecuador, El Salvador y México dan muestras de tener un proceso un tanto más rápido que Cuba, Perú y Colombia.

Opuesto a esto, se encuentra la reunificación que se presenta cuando la relación es de jefe de hogar y sus hijos. Si observamos de nuevo la Figura 3, nos percataremos que las personas que son jefe de familia migran de manera mucho más temprana cuando son sus hijos quienes los reunifican, que en el caso contrario. La mayoría de los casos escogidos, lo hacen antes de los 10 años. Para México al menos más de un $60 \%$ se hace de este modo.

Por otra parte, la Figura 4, nos muestra que los tiempos de reunificación son menores para los colectivos de Perú y Ecuador, cuando primero migra el jefe de hogar, y, a pesar de no tener una muestra suficiente para ver una mejor estimación de la función de supervivencia, los colectivos de México y Colombia presentan probabilidades de reunificación con tiempos más largos.
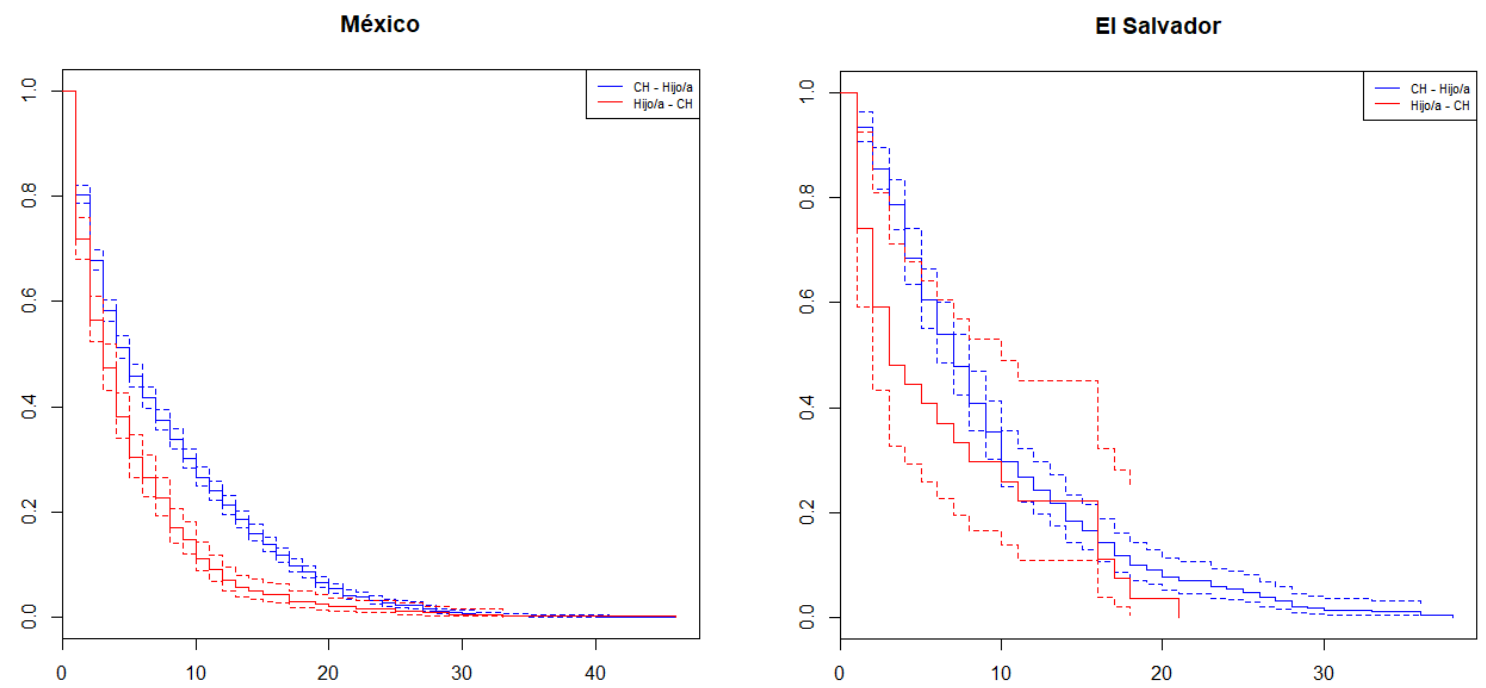

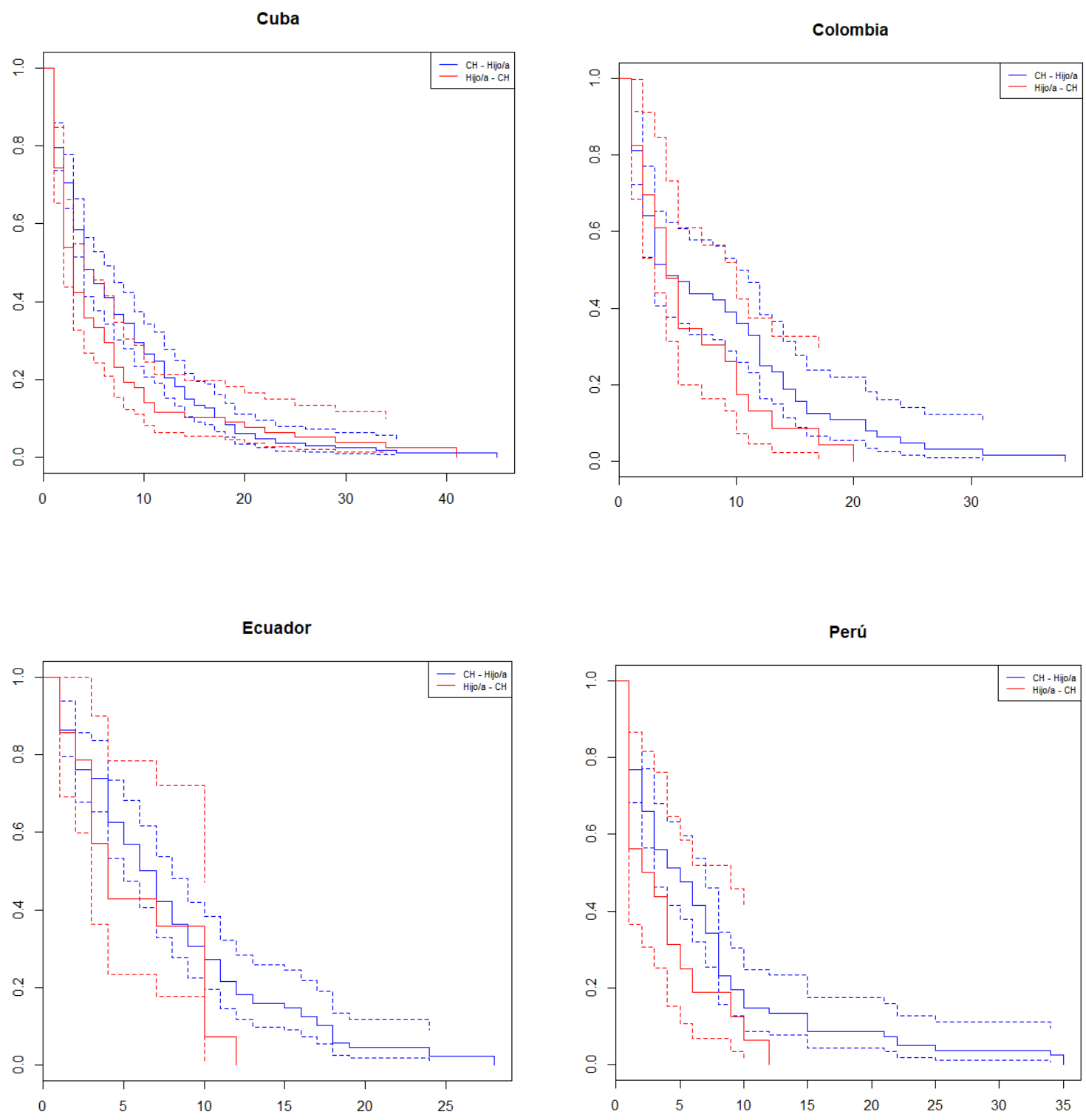

Figura 4. Estimador de Kaplan-Meier para el tiempo de reunificación cuando el jefe de hogar $(\mathrm{CH})$ migra primero que su hijo/a y viceversa.

Fuente: elaboración propia.

\subsection{Modelamiento del tiempo de reunificación}

La Tabla 5, muestra que, para los colombianos, tener hijos entre 0 y 4 años es un factor que retrasa la reunificación. Para Ecuador, es posible decir que mientras pasa el tiempo es más probable que exista una reunificación. Otras variables del mismo país ejercen una disminución en el riesgo de reunificación, como tener escolaridad baja u ocuparse en la preparación y los servicios de alimentos. No se encontró ninguna variable significativa para Perú. En el caso de México, El 
Salvador y Cuba, los resultados muestran algunas variables que retrasan los eventos de reunificación como la edad, ser mujer, y contrario a lo que pasa con Ecuador, entre más años de inmigración, menos probabilidad de reunificación. Además, participar en actividades de extracción.

\section{Tabla 5}

Variables significativas en el modelo de Cox para la reunificación entre Jefe de hogar-Esposola.

\begin{tabular}{|c|c|c|c|c|c|}
\hline COLOMBIA & ECUADOR & PERÚ & MEXICO & $\begin{array}{l}\text { EL } \\
\text { SALVADOR }\end{array}$ & CUBA \\
\hline \multirow[t]{9}{*}{$\begin{array}{l}\text { Tener hijos en la } \\
\text { guardería hasta el } \\
\text { grado } 4(-)\end{array}$} & $\begin{array}{l}\text { Año de } \\
\text { Inmigración } \\
(+)\end{array}$ & & Edad (-) & Edad (-) & Edad (-) \\
\hline & $\begin{array}{l}\text { Grado } 5,6,7, \\
\text { o } 8(-)\end{array}$ & & Sexo: Mujer (-) & $\begin{array}{l}\text { Año de } \\
\text { Inmigración } \\
(-)\end{array}$ & $\begin{array}{l}\text { Año de } \\
\text { Inmigración } \\
(-)\end{array}$ \\
\hline & Grado 9 (-) & & $\begin{array}{l}\text { Año de } \\
\text { Inmigración (-) }\end{array}$ & $\begin{array}{l}\text { Oficina y } \\
\text { soporte } \\
\text { administrativo } \\
(-)\end{array}$ & \\
\hline & Grado $11(-)$ & & Grado: $9(+)$ & & \\
\hline & Grado $12(-)$ & & $\begin{array}{l}4 \text { años de } \\
\text { universidad (+) }\end{array}$ & & \\
\hline & $\begin{array}{l}\text { Preparación y } \\
\text { servicio de } \\
\text { alimentos (-) }\end{array}$ & & $\begin{array}{l}5+\text { años de } \\
\text { universidad (+) }\end{array}$ & & \\
\hline & & & $\begin{array}{l}\text { Actividades de } \\
\text { extracción (-) }\end{array}$ & & \\
\hline & & & Ventas y & & \\
\hline & & & Afines (-) & & \\
\hline
\end{tabular}

Fuente: elaboración propia a partir de datos IPUMS-USA, 2015. 
En el caso donde la reunificación se da entre los jefes de hogar $(\mathrm{CH})$ y sus hijos que se presenta en la Tabla 6, se observa que, para las $\mathrm{CH}$ de Colombia, tener una ocupación en el sector de la construcción ejerce un efecto que disminuye el riesgo de reunificación de los hijos. Este y el caso de México donde ejercer una actividad en servicios comunitarios y sociales, son los únicos que retrasarían los eventos de reunificación. El resto de variables ejercen un efecto positivo en la probabilidad de reunificación entre los jefes de hogar y los hijos.

\section{Tabla 6}

Variables significativas en el modelo de Cox para la reunificación Jefe de hogar - Hijo/a

\begin{tabular}{|c|c|c|c|c|c|}
\hline $\begin{array}{l}\text { COLOMBI } \\
\text { A }\end{array}$ & $\begin{array}{l}\text { ECUAD } \\
\text { OR }\end{array}$ & PERÚ & MÉXICO & EL SALVADOR & CUBA \\
\hline \multirow[t]{6}{*}{$\begin{array}{l}\text { Construcció } \\
\text { n (-) }\end{array}$} & $\begin{array}{l}\text { Año de } \\
\text { inmigraci } \\
\text { ón }(+)\end{array}$ & $\begin{array}{l}\text { Sexo: Mujer } \\
(+)\end{array}$ & $\begin{array}{l}\text { Sexo: Mujer } \\
(+)\end{array}$ & $\begin{array}{l}\text { Año de inmigración } \\
(+)\end{array}$ & Edad (-) \\
\hline & $\begin{array}{l}1 \text { año de } \\
\text { universid } \\
\text { ad (+) }\end{array}$ & $\begin{array}{l}\text { Año de } \\
\text { Inmigración } \\
(+)\end{array}$ & $\begin{array}{l}\text { Año de } \\
\text { inmigración } \\
(+)\end{array}$ & Grado $11(+)$ & $\begin{array}{l}\text { Sexo: } \\
\text { Mujer (+) }\end{array}$ \\
\hline & $\begin{array}{l}2 \text { años de } \\
\text { universid } \\
\text { ad (+) }\end{array}$ & $\begin{array}{l}\text { Arte, } \\
\text { diseño, } \\
\text { entretenimie } \\
\text { nto, } \\
\text { deportes y } \\
\text { medios (+) }\end{array}$ & $\begin{array}{l}\text { Grado 5,6,7, o } \\
8(+)\end{array}$ & $\begin{array}{l}5+\text { años de } \\
\text { universidad (+) }\end{array}$ & $\begin{array}{l}\text { Trabajo en } \\
\text { Producció } \\
\text { n (+) }\end{array}$ \\
\hline & & $\begin{array}{l}\text { Servicios } \\
\text { comunitario } \\
\text { s y sociales } \\
(+)\end{array}$ & Grado $9(+)$ & Construcción (-) & \\
\hline & & & Grado $10(+)$ & $\begin{array}{l}\text { Cuidado y servicio } \\
\text { personal (-) }\end{array}$ & \\
\hline & & & Grado $12(+)$ & Desempleado (-) & \\
\hline
\end{tabular}




$$
\begin{aligned}
& \text { Instalación, } \\
& 4 \text { años de mantenimiento y } \\
& \text { universidad (+) reparación (-) } \\
& \text { Limpieza y } \\
& \text { 5+años de mantenimiento de } \\
& \text { universidad (+) edificios y terrenos }
\end{aligned}
$$$$
(-)
$$

$\begin{array}{ll}\text { Servicios de } & \text { Oficina y soporte } \\ \text { protección (+) } & \text { administrativo (-) } \\ \text { Servicios } & \text { Preparación y } \\ \text { comunitarios y } & \text { servicio de } \\ \text { sociales (-) } & \text { alimentos (-) } \\ & \text { Trabajo en } \\ & \text { Producción (+) } \\ & \text { Profesionales de la } \\ & \text { salud y técnicos (-) } \\ & \text { Transporte y } \\ & \text { movimiento de } \\ & \text { materiales (-) } \\ & \text { Ventas y afines (-) }\end{array}$

Fuente: elaboración propia a partir de datos IPUMS-USA, 2015.

En el análisis previo los resultados difieren en las variables que resultan significativas, se destacan categorías creadas para los colectivos colombianos y peruanos y la incidencia es positiva por parte de las ocupaciones profesionales. No obstante, en los dos tipos de reunificación estudiados, la influencia de las ocupaciones del sector servicios y de baja cualificación y remuneración es evidente. De igual manera, es notoria la influencia positiva de tener más educación (años de universidad) y la negativa de tener poco (hasta noveno grado). Por tanto, los resultados no difieren demasiado en cuanto a que mantienen el sentido general del análisis, más bien son complementarios. De la misma forma se muestra como para las reunificaciones de los hijos aparecen más variables significativas, lo que habla de la intensidad respecto del otro tipo de reunificación considerado, sin llegar a cuantificarse. 


\section{CONCLUSIONES}

Para resaltar la importancia de las redes familiares dentro de los sistemas migratorios se ha realizado una introducción teórica sobre ellas con el fin de ubicar el hecho de poder presentar elementos tan importantes en el desarrollo de la migración, como lo es la reunificación. La primera, la red familiar como entidad, es el evidente resultado de un proceso de maduración por la inserción de los migrantes en destino, y la segunda, la reunificación, como mecanismo que mantiene los vínculos y proporciona retroalimentación o feedback en los procesos migratorios para su continuidad, representado en nuevas migraciones, pero también en intercambios de información, dinero, bienes, etc.

Un aspecto que se encuentra de manera transversal, es que los jefes de hogar se feminizan con el tiempo. Dicho comportamiento pareciera ser más adoptado por imposiciones del sistema económico y político que ha motivado el retorno de hombres principalmente, y no por planeación previa en origen, aunque pueda existir. La feminización podría constituirse en un mecanismo/actividad dentro del sistema y sus causas se pueden encontrar en muchos otros factores sociales o económicos.

Por ejemplo, la migración de retorno experimentada por México y que deja manifiesta la decisión de dejar un miembro anclado no solo en caso de poder volver sino muy seguramente para asegurar la manutención. Pero, a pesar de que existen cifras recopiladas por gobiernos y diferentes institutos e investigadores sobre el retorno, la observación de los procesos de los colectivos emigrados que parecen estar ligados a este asunto particular, siempre será parcial dado que otros factores intervienen como el incremento en la emigración de personas solas, la mortalidad, el re-emigración a otros países, etc. Se asume una correlación positiva pero no se sugiere causalidad, debido a que la última necesita de la interacción y análisis con otras variables.

De la misma manera, las tipologías de conformación de los hogares conservan a las familias nucleares como unidad preponderante en aumento para todos los colectivos, con algunos más implicados que otros de acuerdo con la clasificación. A pesar de no trabajar directamente con variables del retorno, sabemos por otras fuentes que existe, pero que dicho retorno no se hace de la unidad familiar completa para conservar algún tipo de anclaje. De otra parte, las familias pudieron haber enviado un pionero y solo éste es captado en el censo. De igual forma, no puede dejarse atrás que el hecho más común es que se encuentren allí por trabajo o estudios. El hecho 
que existan diferencias tan marcadas de los porcentajes de hogares nucleares en los países centroamericanos, muestra la influencia de la cercanía debido a la importancia de un polo de atracción de migración internacional como lo son los Estados Unidos. La tradición migratoria también es expresada por los porcentajes de familias nucleares y por la preponderancia de formas más complejas como los hogares extendidos, como se observó de manera más prominente en los países centroamericanos.

Los hogares en la muestra se presentan mayoritariamente en parejas connacionales, ello refleja de algún modo la preferencia por las relaciones con el mismo colectivo (posible endogamia) y puede llegar a constituirse como una hipótesis en la que se presente como un factor positivo en la cohesión de la red migratoria.

Otro aspecto relevante resulta ser la influencia del orden en que realizan las migraciones y el sexo del jefe del hogar sobre la dinámica del proceso. Por una parte, se muestran varios tipos de migración entre ellos, el que se caracteriza por que el jefe del hogar migra primero y luego lo hace el esposo/a. En este tipo de migración, la dominancia masculina cuando se migra primero es mayor, pero cuando migra primero el esposo/a y luego el jefe de hogar, esta última es en su mayoría mujeres, con lo que al final, el pionero también resulta ser el hombre. Esto puede derivar en alguna hipótesis acerca de la selectividad por sexo en la actividad del pionerismo y que puede ser diferenciada en un sistema con diferente valoración en la equidad de género.

Un factor que influye sobre las configuraciones de los hogares y que debe ser tomado en cuenta, sobre todo proceso migratorio es el retorno. A pesar de que las cifras parecieran mostrar un retorno vigoroso de migrantes sobre todo hacia América Central y otros países, no es el único hecho que puede causar el incremento de algunos tipos de hogar particular si contamos con que siguen llegando personas solas y que hay otras que migran a otros países como Canadá o España. También sería importante revisar si existen procesos de mortalidad asociados con los arreglos de hogar, así como la influencia de la reunificación sobre el retorno.

El análisis del riesgo de reunificación a través de la metodología de Kaplan-Meier, plantea varios aspectos que son relevantes en el desarrollo de las redes personales. En primer lugar, se evidencia que la reunificación entre el jefe del hogar y el esposo/a, sucede más rápido cuando se da en ese 
orden, opuesto a lo que pasa cuando la reunificación se da en la pareja formada por el jefe de hogar y los hijos. Esta diferencia permite inferir que puede existir una estrategia de migración previa (en origen), aunque también se cuenta con un gran porcentaje de familias que lo hacen al tiempo. Así, la estrategia de enviar el hijo primero puede ser debido a la presencia de otros familiares previamente en el lugar de destino.

No obstante, que los países tengan diferencias en los tiempos de reunificación entre ellos, resaltaría el hecho de qué tan preparado llega a estar un colectivo para poder concretar una reunificación en términos del desenvolvimiento del colectivo y de su inserción laboral, social, etc. Estas diferencias determinan que las actividades de reunificación constituyen un mecanismo por el cual, se promueve y se mantienen procesos migratorios familiares y de cohesión de los colectivos.

De la misma forma, el análisis muestra que existen variables significativas y que intervienen positivamente para aumentar la probabilidad de realizar una reunificación de un esposo o un hijo, y que estas variables son diferentes en cada caso. En muchos, los efectos positivos son congruentes con lo aferrado que se muestre el colectivo en destino con el incremento en los años de migración, el aumento en el nivel educativo, o el tener algunas ocupaciones particulares.

También existen factores que producen un efecto negativo, es decir, que disminuyen la probabilidad de reunificación. Un ejemplo contundente, es el que arroja la variable año de inmigración para El Salvador, México y Cuba que podría llegar a explicarse a una cuestión de estabilidad un tanto por cercanía, ya que debido a esto que una pareja permanezca junta es cada vez menos obligatorio (si fuese una migración a España, por ejemplo) y por tanto la reunificación se da cuando exista más estabilidad por lo que tomaría más tiempo. De otro lado se encuentran algunas profesiones que suelen ser de trabajo duro o poco remunerado, con lo cual se supone que, por ejemplo, en el caso de las reunificaciones con los hijos, no es posible cubrir los costos, ni dedicar el tiempo suficiente que implican al tener una ocupación de este tipo.

En análisis previos que no incluían la condición de haberse casado en el origen se mostraban resultados acerca de más presencia de hombres jefes de hogar sobre todos los tipos de reunificación, así como que todas las curvas de los estimadores de Kaplan-Meier presentaran reunificaciones más rápidas cuando el Jefe de Hogar era el primero en el orden de migración. No obstante, los resultados son sesgados dado que muchos pudieron, por poner un ejemplo, haberse 
casado en Estados Unidos y luego haber reunificado un hijo del mismo o de otro matrimonio. Por tanto, para estudiar el proceso más detallado debe hacerse también un tanto por falta de información en el censo.

Respecto de la influencia de las políticas como los marcos para la integración que suceden en la Comunidad Andina de Naciones, se destaca la diferencia que existe respecto a la feminización de los colectivos y también la poca concentración respecto de países representativos de América Central y El Caribe. No se observa una influencia sobre los tiempos de reunificación de los tipos de migración establecidos. Al parecer es muy poco lo que puede contribuir al análisis la inclusión de este elemento como factor diferencial.

Del mismo modo, los resultados acerca del proceso de feminización, que pueden ser tomados de una manera transversal e indispensable en los estudios migratorios el incremento en los flujos de mujeres y la relevancia adquirida en los contextos de destino, debido a que en algunos casos que existe un cambio en sus modos de vida en los que se incluyen la influencia de los roles de género en la emancipación y responsabilidad sobre los hogares que han adquirido las mujeres (Oso, 2008). Sin embargo, a pesar del proceso de feminización general, los procesos de reunificación aún comportan en algunos casos una dominancia del sexo masculino como jefe de hogar que reunifica.

Por último, las evidencias anteriores basadas en las diferencias de las decisiones de los hogares latinoamericanos nos dejan ver que en sí mismas, la conformación de una red familiar es un mecanismo dentro del sistema migratorio que se ha planteado. De igual forma, se deduce que este mecanismo puede llegar a ser más o menos efectivo, en lo relacionado con la fuerza de atracción de más migrantes, dependiendo del colectivo emigrado y los niveles de preparación, ocupación e inserción que tengan sus contactos en destino. También debe tomarse en cuenta las condiciones económicas, sociales y políticas que imponen los destinos en el desarrollo de los procesos migratorios. Con los casos que se han seleccionado, es posible inferir que el método usado para el sistema propuesto, es posible de realizar con otros sistemas a nivel mundial incluso, con lo cual, trabajos posteriores incluirán dichas comparaciones con el fin de encontrar generalidades acerca de la reunificación. 


\section{REFERENCIAS}

(1) Arriagada, I. (2007). Familias latinoamericanas: cambiantes, diversas y desiguales. Papeles de Población, 13(53), 9-22

(2) Bakewell, O. (2014). Re-launching migration systems. Migration Studies. 2(3), 300-318

(3) Canales, A. (2017). La migración internacional en los modelos neoclásicos. Una perspectiva crítica. Huellas de la Migración, 2(3), 11-36.

(4) De Vos, S. (1987). Latin American Households in Comparative Perspective. Population Studies, 41(3), 501-517

(5) Domingo, A., y Bayona, J. (2010). Los hogares de la población de nacionalidad extranjera en España en el año 2001. Papers de demografía, 95(3), 731-754.

(6) Frizzell, R.W. (1987). "Migration Chains to Illinois: The Evidence from German-American Church Records". Journal of American Ethnic History, 7(1), 59-73.

(7) Giorguli, S. y Bautista, A. (2018) Radiografía de la migración de retorno 2015. Notas para la integración de los retornados. Número 1. Sistema Nacional de información sobre migración de retorno y derechos sociales, barreras para la integración. https://migracionderetorno.colmex.mx/indicadores/, Última consulta: 14/09/19.

(8) Gurak, D., y Kritz, M. (2016). Pioneer settlement of US immigrants: Characteristics of pioneer migrants and places. Demographic Research. 34(25), 705-740

(9) Herrera. G. (2011). Cuidados globalizados y desigualdad social reflexiones sobre la feminización de la migración andina. Nueva Sociedad, 233, 87-97.

(10) Hedström, P., y P. Bearman, eds. (2009). What is Analytical Sociology All About? An Introductory Essay. En libro: The Oxford handbook of analytical sociology. Oxford University. Nueva York, Estados Unidos.

(11) Jasso, G. y Rosenzweig, M. (1986) Family Reunification and The Immigration Multiplier: U.S. Immigration Law, Origin-Country Conditions, And The Reproduction of Immigrants. Vol 23, Num 3, pp. 291-311. https://doi.org/10.2307/2061432.

(12) Kritz, M., Lim, L., y Zlotnik, H. (1992) International Migration Systems: A global approach. Oxford University Press. Nueva York, Estados Unidos.

(13) Laslett, P. y Wall, R. (1972). Household and Family in Past Time. Cambridge University Press. https://doi.org/10.1017/CBO9780511561207

(14) León, F. (2016). No más barcos de Coleman. Repensando las relaciones micro-macro. Memorias del XII Congreso Español de Sociología. Gijón (ESP).

(15) Mabogunje, A. (1970). Systems Approach to a Theory of Rural-Urban Migration. Geographical Analysis, 2(1) 1-18. 
(16) Massey, D. (1990). Social Structure, Household Strategies, and the Cumulative Causation of Migration, Population Index, 56(1), 3-26.

Massey, D., y Aysa, M. (2011). "Social Capital and International migration from Latin America". International Journal of Population Research, International Journal of Population Research, 2011(834145), 1-18.

(18) Martínez, J. (2001) Reflexiones sobre la gobernabilidad de la migración internacional en América Latina. Migraciones Internacionales, ISSN-e 1665-8906, Vol. 1, №. 1, págs. 88110

(19) Minnesota Population Center (2018). Integrated Public Use Microdata Series, International: $\begin{array}{llll}\text { Version } & 7.1 & \text { [dataset]. } & \text { Minneapolis, } \\ \text { MN: }\end{array}$ https://doi.org/10.18128/D020.V7.1

(20) Nobles, J. (2013). Migration and Father Absence: Shifting Family Structure in Mexico. Demography, 50(4), 1303-1314. doi:10.1007/s13524-012-0187-8

(21) Oso, L. (2008) Migración, género y hogares transnacionales. En libro: La inmigración en la sociedad española: una radiografía multidisciplinar. págs. 561-586. Ediciones Bellaterra.

(22) Pekin, H. (1989). Effects of Migration on Family Structure. International Migration, 27(2), 281-293. doi:10.1111/j.1468-2435.1989.tb00257.x

(23) Prieto, V., Pellegrino, A., y Koolhaas, M. (2015) Intensidad y selectividad de la migración de retorno desde España y los Estados Unidos hacia América Latina. En libro: Retorno en los procesos migratorios de América Latina. Conceptos, debates y evidencias. Serie de investigaciones No. 16. Editorial: ALAP - Asociación Latinoamericana de Población.

(24) R Core Team (2017). R: A language and environment for statistical computing. R Foundation for Statistical Computing, Vienna, Austria. URL https://www.R-project.org/.

(25) Rass, C. (et al.). (2018). What Is in a Migration Regime? Genealogical Approach and Methodological Proposal. En libro: Was ist ein Migrationsregime? What Is a Migration Regime? Springer Fachmedien Wiesbaden;Springer VS.

(26) Recaño, J. (2002). El papel de las redes en los procesos de migración interna. Revista de Demografía Histórica, 20 (1), 15-20.

Ruggles, S., Genadek, K., Goeken, R., Grover, J., and Sobek, M. Integrated Public Use Microdata Series: Version 6.0 [dataset]. Minneapolis: University of Minnesota, 2015. http://doi.org/10.18128/D010.V6.0.

(28) Takenaka, A., y Pren, K. (2010). Determinats of Emigration: Comparin Migrants' Selectivity form Peru and Mexico. American Academy of Political and Social Science, 630, 178-193.

(29) Wallerstein, I. (1979). El moderno sistema mundial: la agricultura capitalista y los orígenes de la economía europea en el siglo XVI. Madrid, Siglo XXI. 
(30) Woodward, M. (2014). Epidemiology: Study, Design, and Data Analysis. Taylor and Francis Group. 